\title{
PEMBUATAN PEKTIN DARI KULIT MARKISA KUNING (Passiflora edulis flavicarpa) YANG DIMODIFIKASI
}

\author{
Riyan Riski Sarandi, Yusro Alhusna, Setiaty Pandia \\ Departemen Teknik Kimia, Fakultas Teknik, Universitas Sumatera Utara, \\ Jl. Almamater Kampus USU, Medan 20155, Indonesia \\ Email : rsarandi26@gmail.com
}

\begin{abstract}
Abstrak
Kulit markisa kuning (Passiflora edulis flavicarpa) merupakan limbah dari buah markisa kuning yang dapat dimanfaatkan untuk diekstrak menjadi pektin. Tujuan dari penelitian ini adalah untuk mengekstraksi dan memodifikasi pektin dari kulit markisa kuning (Passiflora edulis flavicarpa) dari jenis HMP (High Metoxyl Pectin) ke jenis LMP (Low Metoxyl Pectin) dan membandingkan karakteristiknya. Penelitian ini meliputi tahap ekstraksi pektin lalu dilanjutkan dengan modifikasi $\mathrm{pH}$ pektin dengan menggunakan natrium hidroksida dan asam klorida. Hasil penelitian menunjukkan bahwa modifikasi pektin berhasil menurunkan nilai derajat esterifikasi (\%DE) dari jenis HMP menjadi LMP. Pektin modifikasi yang dihasilkan juga memiliki warna yang sedikit lebih pucat atau tidak terlalu kecoklatan dan tidak memiliki bau. Analisa gugus fungsi yang dilakukan didapat bahwa perubahan pada puncak puncak dalam FTIR menunjukkan penurunan angka metilasi dari grup -COOH. Pektin yang dihasilkan juga menunjukkan fenomena membentuk gel oleh pertukaran ion dengan asam dan terdapat gugus baru pada pektin modifikasi yaitu gugus $\mathrm{C}=\mathrm{C}$ (Aromatik). Yield pektin dari proses ekstraksi adalah 2,54\% dan yield yang dihasilkan setelah proses modifikasi adalah $94,73 \%$.
\end{abstract}

Kata Kunci : pektin, HMP, LMP, kulit markisa kuning, derajat esterifikasi

\begin{abstract}
Passion fruit (Passiflora edulis flavicarpa) peel, a waste from yellow passion fruit industry could be utilized to extract pectin. The objectives of this study were to extract and modify yellow passion fruit pectin from HMP (High Metoxyl Pectin) to LMP (Low Metoxyl Pectin) and compare characteristic both of them. This research was conducted in pectin extraction and then modify $\mathrm{pH}$ of pectin used natrium hydroxide and chloric acid. The result of this research showed that modified pectin succeded to decrease degree of esterification from HMP to become LMP. Modified pectin had a brighter color or not too browny and no aroma. Function group analysis showed that shift in peaks in FTIR confimed a decrease of number methylated-COOH group. The resulting pectins also gelled by charge compensation with acid. It was found a new function group in modified pectin, which was of $C=C$ (aromatic) group. The yield of pectin by extracting was $2,54 \%$ and yiled of pectin after modifying was $94,73 \%$.
\end{abstract}

Keywords :pectin, HMP, LMP, yellow passion fruit, degree of esterification

\section{Pendahuluan}

Pektin merupakan polisakarida komplek yang mengandung asam galakturonat yang dihubungkan oleh $\alpha-(1-4)$ glikodidik. Menurut peraturan FAO, pektin harus mengandung sedikitnya $65 \%$ asam galacturonat. Zat ini biasanya ditemukan pada dinding sel dan lamella tengah tanaman. Derajat esterifikasi adalah salah satu sifat yang mempengaruhi aplikasi dari pektin seperti menentukanjel alami pektin. Nilai presentase DE diatas 50\% diklasifikasikan sebagai high methyl ester (HMP) sementara pektin dengan nilai DE dibawah 50\% diklasifikasikan sebagai low methyl ester (LMP). Yield dan nilai DE dari pektin bervariasi menurut jenis kulit buah, parameter ekstraksi dan juga ekstraktor yang digunakan [13]. Pektin biasanya digunakan dalam sains makanan sebagai zat pengembang, pengemulsi, pembentuk struktur dan stabilitas. Dalam bidang nutrisi pektin menunjukkan nilai kolesterol rendah dan kolesterol lipoprotein dengan densitas rendah yang menguntungkan bagi kesehatan manusia, serta juga pektin banyak digunakan dalam bidang kosmetik dn farmasi [9].

Pektin yang umum terdapat pada limbah pertanian adalah pektin jenis HMP. Pektin jenis ini akan membentuk gel pada $\mathrm{pH}$ rendah dan dengan adanya padatan terlarut dalam jumlah besar. Gel yang terbentuk akan mudah larut dalam air sehingga praktis pektin jenis HMP tidak biasa digunakan sebagai adsorben logam berat. Semakin rendah kadar metoksil pektin maka sifat pembentukan jellinya akan semakin berkurang, sehingga jenis pektin yang dapat digunakan sebagai adsorben adalah LMP. LMP dapat dihasilkan dari HMP dengan proses demetilasi. Demetilasi adalah proses penurunan kadar metoksil pektin. Proses ini dilakukan untuk mendapatkan LMP dari bahan HMP. Low 
methoxyl pectin sendiri banyak digunakan sebagai gelling agent pada produksi selai rendah gula. Selain itu LMP juga berpotensi untuk digunakan sebagai senyawa anti kanker [6].

Markisa kuning merupakan famili dari Passifloraceae yang merupakan buah eksotik dengan rasa yang khas. Secara komersial buah ini banyak ditanam di daerah tropis dan sub tropis di bumi. Jus markisa adalah produk yang sangat populer di pasaran. Limbah yang dihasilkan selama proses pembuatannya meliputi bagian kulit dan bagian biji. Kulit buah markisa yang dibuang jumlahnya mendekatii setengah dari massa buah markisa secara keseluruhan. Sebagai limbah utama yang dihasilkan, hal ini memiliki masalah yang dapat mempengaruhi polusi di lingkungan. [12]. Kulit markisa mengandung jumlah pektin yang cukup banyak [11].

Ketersedian limbah kulit buah markisa kuning sebagai sumber biomassa tanaman dan bahan organik yang cukup besar serta belum banyak pemanfaatannya memerlukan cara penanganan yang tepat. Oleh karena itu kulit buah markisa kuning tersebut dapat dimanfaatkan sebagai salah satu bahan baku pembuatan pektin dan juga dapat dimodifikasi sehingga menambah kegunaannya.

\section{Teori}

Markisa kuning merupakan salah satu kelompok markisa asam tergolong dalam famili Passifloraceae atau disebut buah Rola (Yellow Passion Fruit). Tanaman ini merupakan tanaman herba atau berkayu, dan memiliki sulur. Ruas batang lebih panjang dari pada markisa ungu 7-10 $\mathrm{cm}$ dengan sulur muda berwarna kecoklatan. Bentuk daun menjari dengan ukuran daun lebih besar dan lebih tebal daripada markisa ungu, panjang daun 10-13 cm, dan lebar 9-12 cm, daun muda berwarna hijau, sedangkan tangkai berwarna hijau kecoklatan [1]. Dalam proses pengolahan markisa untuk menghasilkan sari buah markisa, juga dihasilkan limbah. Makin meningkatnya produksi pengolahan markisa berarti akan meningkat pula limbah yang dihasilkan. $51 \%$ dari buah markisa terdiri dari kulit, maka terdapat limbah kulit markisa yang cukup banyak ton yang belum dimanfaatkan. Padahal kulit markisa mengandung pektin yang tinggi yaitu sebesar 14\% [4].

Pektin merupakan polimer linear dari asam Dgalakturonat yang berikatan dengan 1,4- $\alpha$ glikosidik. Asam D-galakturonat memiliki sturktur yang sama seperti struktur D-galaktosa, perbedaannya terletak pada gugus alkohol primer C6 yang memiliki gugus karboksilat. Sebagian gugus karboksilat pada polimer pektin mengalami esterifikasi dengan metil menjadi gugus metoksil dan biasanya mengandung sekitar 8,0 - 11,0\% gugus metoksil [8].
Pektin juga membawa subtituen bukan gula, metanol pada pokoknya, asam asetat, asam fenol dan terkadang terdapat grup amida. Esterifikasi asam galakturonat dengan metanol atau asam asetat merupakan struktur paling penting dari karakteristik kimia pektin [2].

Bentuk dari rantai molekul Pektin ditujukkan oleh gambar 1 .

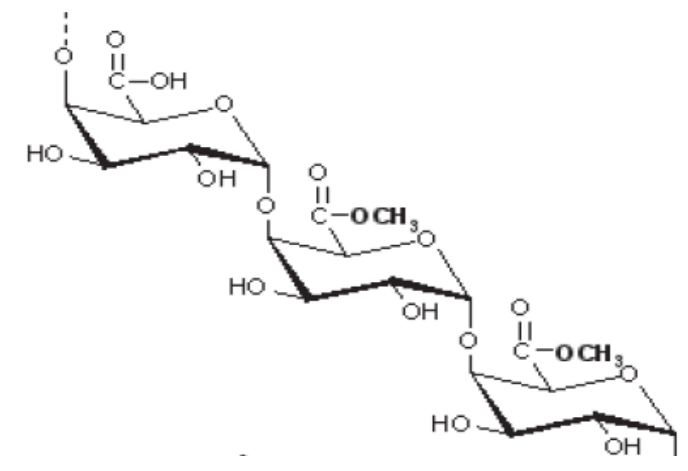

Gambar 1. Rantai Molekul Pektin [10]

Tabel 1 merupakan standar mutu pektin berdasarkan standar mutu Internasional Pectin Producers Association :

Tabel 1.Standar Mutu Pektin Berdasarkan Standar Mutu Internasional Pectin Producers Association [5]

\begin{tabular}{|c|c|}
\hline Faktor Mutu & Kandungan \\
\hline Kekuatan gel, grade min & 150 \\
\hline $\begin{array}{c}\text { Kandungan metoksil: } \\
\text { tinggi, \% } \\
\text { Pektin metoksil } \\
\text { rendah, \% }\end{array}$ & $>7,12$ \\
\hline $\begin{array}{c}\text { Kadar asam } \\
\text { galakturonat, \% min }\end{array}$ & $35,7,12$ \\
\hline Kadar air, \% maks & 12 \\
\hline Kadar abu, \% maks & 10 \\
\hline $\begin{array}{c}\text { Derajat esterifikasi untuk: } \\
\text { Pektin ester } \\
\text { tinggi, \% min } \\
\text { Pektin ester } \\
\text { rendah, \% min }\end{array}$ & 50 \\
\hline Bilangan asetil, \% & 50 \\
\hline Berat ekivalen & $600-800$ \\
\hline
\end{tabular}


Pektin yang umum terdapat pada limbah pertanian adalah pektin jenis HMP. Pektin jenis ini akan membentuk gel pada $\mathrm{pH}$ rendah dan dengan adanya padatan terlarut dalam jumlah besar. Gel yang terbentuk akan mudah larut dalam air sehingga praktis pektin jenis HMP tidak biasa digunakan sebagai adsorben logam berat. Semakin rendah kadar metoksil pektin maka sifat pembentukan jellinya akan semakin berkurang, sehingga jenis pektin yang dapat digunakan sebagai adsorben adalah LMP. LMP dapat dihasilkan dari HMP dengan proses demetilasi. Demetilasi adalah proses penurunan kadar metoksil pektin. Proses ini dilakukan untuk mendapatkan LMP dari bahan HMP. Low methoxyl pectin sendiri banyak digunakan sebagai gelling agent pada produksi selai rendah gula. Selain itu LMP juga berpotensi untuk digunakan sebagai senyawa anti kanker [6]. Bila dilihat dari adanya gugus aktif, maka LMP juga berpotensi sebagai biosorben logam-logam berat. Bila dilihat dari bahan yang digunakan, ada empat metode proses demetilasi. Keempat metode itu adalah demetilasi dengan asam, basa, enzim dan menggunakan ammonia dalam alkohol [7].

\section{Metodologi Penelitian \\ Alat dan Bahan}

Bahan baku dari penelitian ini adalah kulit markisa kuning dari beberapa pasar buah di Medan, sibolangit dan Berastagi. Bahan tambahan adalah aquades $\left(\mathrm{H}_{2} \mathrm{O}\right)$, asam klorida $(\mathrm{HCl})$, etanol $\left(\mathrm{C}_{2} \mathrm{H}_{5} \mathrm{OH}\right)$, natrium hidroksida $(\mathrm{NaOH})$ dan aseton $\left(\mathrm{C}_{3} \mathrm{H}_{6} \mathrm{O}\right)$.

Peralatan utama yang digunakan adalah hot plate, timbangan, oven, dan indikator $\mathrm{pH}$. Peralatan analisa yang digunakan adalah Fourier Transform Infra Red (FTIR) dan buret.

\section{Prosedur Percobaan}

Penelitian ini dilakukan di Laboratorium Kimia Organik, Fakultas Teknik, Teknik Kimia, Universitas Sumatera Utara (USU), Medan.

Proses ekstraksi dilakukan dengan terlebih dahulu denganmengeringkan kulit markisa selama 3 jam didalam oven, setelah itu kulit markisa kuning diblender halus, kemudian ditambahkan air biasa dengan perbandingan 1:15 (v/v) lalu diaduk dan ditambahkan $\mathrm{HCl}$ 0,5 N sampai pH 2. Campuran dipanaskan pada suhu $60-70{ }^{\circ} \mathrm{C}$ selama 2 jam lalu disaring dan dibiarkan dingin pada temperatur kamar. Ditambahkan alkohol 96\% dengan perbandingan 1:2 (v/v) dan dibiarkan selama 16 jam. Setelah itu campuran di saring dan didapatkan pektin basah yang lalu dicuci pertama dengan alkohol asam 70\%, lalu alkohol $70 \%$ kedua dan terakhir dengan alkohol 96\%. Setelah itu pektin dikeringkan dalam oven $40^{\circ} \mathrm{C}$ sampai kering.

Proses modifikasi pektin yaitu Proses modikasi ini di muali dengan melarutkan pektin markisa dalam air suling sampai $1,5 \%$. Lalu $\mathrm{pH}$ ditingkatkan dengan $\mathrm{NaOH} 3 \mathrm{~N}$ sampai 10 lalu di inkubasi dalam oven bersuhu $55^{\circ} \mathrm{C}$ selama 1 jam. Lalu campuran didinginkan sampai temperatur kamar. Setelah itu $\mathrm{pH}$ campuran disesuaikan menjadi 3 dengan menggunakan $\mathrm{HCl} 3 \mathrm{~N}$ dan disimpan semalaman. Campuran diendapkan dengan alkohol $96 \%$, dan didiamkan dalam es selama 2 jam. Disaring dan residu pektin kemudian dicuci dengan aseton. Lalu dikeringkan dalam oven sampai bisa diblender kering dan diayak 60 mesh.

Proses analisa derajat esterifikasi yaitu 0,2 gram pektin kering di basahi dengan etanol dan dilarutkan dengan aquades dan diaduk sampai larut sepenuhnya. Lalu campuran ditambahkan 3 tetes phenoftalein dan dititrasi dengan $\mathrm{NaOH} 0,1$ N. Hasil titrasi dicatat dan di sebut dengan initial titration. Initial titration menunjukkan jumlah group korboksil bebas. Lalu sampel ditambahkan $10 \mathrm{ml} \quad 0,1 \mathrm{~N} \quad \mathrm{NaOH}$ untuk menetralkan polygalacturonic acid dan sampel sampel dikocok kuat, setelah itu didiamkan sselama 2 jam pada temperatur kamar untuk de-esterify pectin. Setelah itu sampel ditambahkan $\mathrm{HCl} 0,1 \mathrm{~N}$ untuk menetralkan natrium hidroksida dan di kocok sampai warna pink sampel hilang. Lalu sampel ditambahkan 3 tetes phenoftalein lagi dan dititrasi dengan $\mathrm{NaOH}$ 0,1 N. Dicatat volume $\mathrm{NaOH}$ yang digunakan dan di sebut final titration. Final titration menunjukkan jumlah group karboksil teresterifikasi. Nilai DE dihitung menggunakan rumus 1 .

$$
\mathrm{DE}=\frac{\text { final titration }}{\text { initial titration }+ \text { final titration }} \times 100 \%
$$

Keterangan:

$$
\begin{aligned}
& \mathrm{DE} \quad=\text { Derajat Esterifikasi }(\%) \\
& \text { Final Titration } \quad=\text { jumlah } \mathrm{NaOH} \text { yang } \\
& \text { digunakan pada titrasi terakhir }(\mathrm{ml}) \\
& \text { Initial Titration }=\text { jumlah } \mathrm{NaOH} \text { yang digunakan } \\
& \text { pada titrasi awal }(\mathrm{ml})
\end{aligned}
$$

\section{Hasil Penelitian \\ Karakteristik Pektin}

Untuk membandingkan karakteristik dari pektin tanpa modifikasi dan modifikasi dapat diamati dari warna, tekstur dan bau dari pektin. Berikut merupakan gambar dari pektin tanpa modifikasi dan modifikasi ditunjukkan pada gambar 2 dan 3 . 


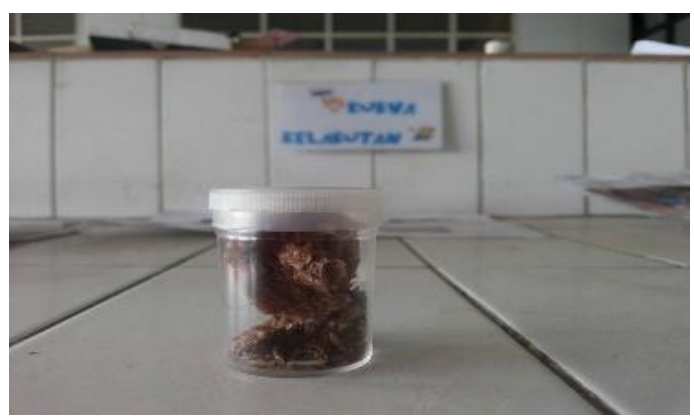

Gambar 2. Pektin Tanpa Modifikasi

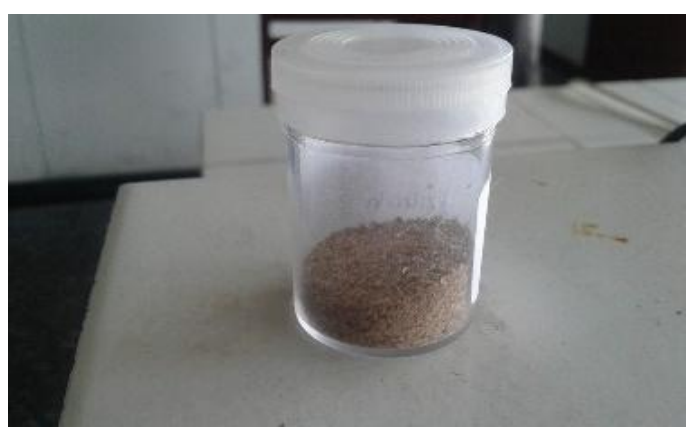

Gambar 3. Pektin Modifikasi

Dari gambar pektin 2 dan 3 dapat diamati bahwa pektin tanpa modifikasi kering berwarna kecoklatan dan berbau, dan pektin modifikasi memiliki warna yang sedikit lebih pucat atau tidak terlalu kecoklatan dan tidak memiliki bau. pektin dapat berupa serbuk kasar atau halus, berwarna putih kekuningan, kelabu atau kecoklatan hampir tidak berbau dan mempunyai rasa musilago [14].

Bau yang dihasilkan pada pektin tanpa modifikasi dapat disebabkan oleh penggunaan kertas saring tipis yang terus menerus sehingga sisa dari hasil penyaringan sebelumnya membentuk sedikit bau yang dihasilkan. Tetapi dari segi warna pektin yang dihasilkan telah sesuai dengan literatur yang disebutkan

\section{Karakteristik Gugus Fungi pada Pektin Tanpa Modifikasi dan Pektin Modifikasi dengan Spektrofotometri FTIR \\ Untuk membandingkan karakteristik gugus} fungsi dari pektin tanpa modifikasi dan modifikasi perlu dilakukannya analisa spektrofotometri Fourier Transform Infra Red (FTIR) sehingga dapat dilihat perubahan dari gugus fungsi setelah proses modifikasi. Berikut merupakan grafik dari hasil analisa FTIR yang ditunjukkan pada gambar 4 dan 5 .

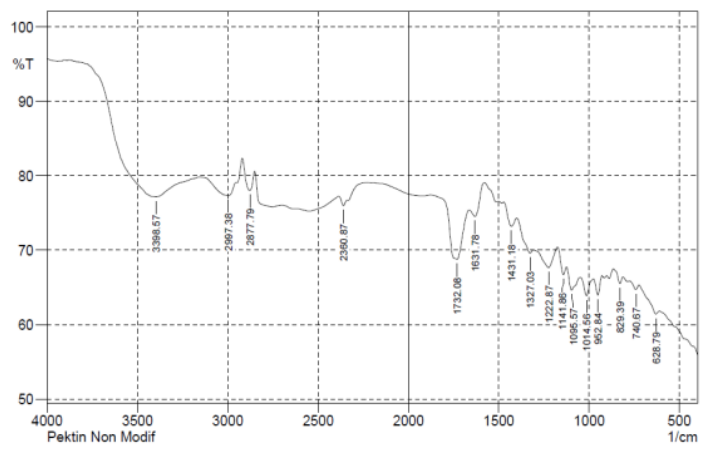

\section{Gambar 4. Hasil Analisa FTIR Pektin Tanpa Modifikasi}

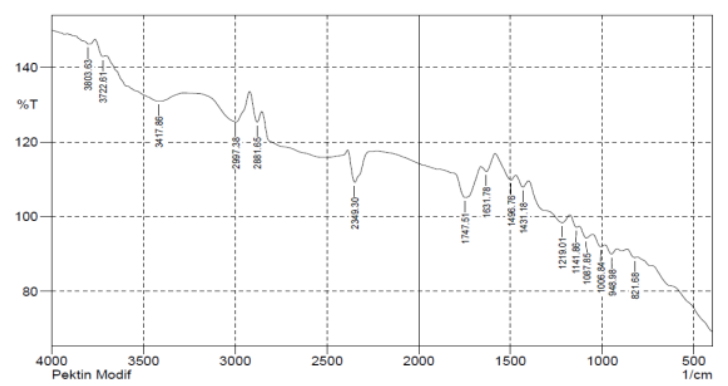

\section{Gambar 5. Hasil Analisa FTIR Pektin Modifikasi}

Gambar 4 menunjukkan karakter dari gugus fungsi pektin tanpa modifikasi. Pada rentang gelombang 2997,38 $\mathrm{cm}^{-1}$ terdapat bidang O-H dari asam karboksilat dan panjang gelombang 1732, $08 \mathrm{~cm}^{-1}$ terdapat grup RCOOR dari gugus ester. Dimana pada gambar ini terlihat bahwa tingkat kecuraman transmitansi dari gugus ester lebih curam dari gugus asam karbokisilat [3]. Hal ini membuktikan bahwa jumlah gugus ester lebih banyak dari gugus asam karboksilat. Sedangkan pada gambar 5 menunjukkan karakter dari gugus fungsi pektin modifikasi. Pada rentang gelombang $2997,38 \mathrm{~cm}^{-1}$ terdapat bidang O-H dari asam karboksilat dan panjang gelombang $1747,51 \mathrm{~cm}^{-1}$ terdapat grup RCOOR dari gugus ester [3]. Dimana pada gambar ini terlihat bahwa tingkat kecuraman transmitansi dari gugus ester tidak lebih curam dari gugus asam karboksilat. Hal ini membuktikan bahwa jumlah gugus ester lebih sedikit dari gugus asam karboksilat.

Perubahan pada puncak puncak dalam FTIR menunjukkan penurunan angka metilasi dari grup - COOH. Pektin yang dihasilkan juga menunjukkan fenomena membentuk gel oleh pertukaran ion dengan asam dan merupakan salah satu karakteristik dari LMP [15]. Selain itu dapat dilihat bahwa terdapat gugus baru pada pektin modifikasi yaitu gugus $\mathrm{C}=\mathrm{C}$ (Aromatik). 


\section{Analisa Derajat Esterifikasi Pektin}

Adapun tabel 2 di bawah ini menunjukkan hasil analisa derajat esterifikasi dari pektin tanpa modifikasi dan modifikasi. Datanya sebagai berikut:

Tabel 2. Hasil Analisia Derajat Esterifikasi Pektin Tanpa Modifikasi dan Modifikasi

\begin{tabular}{|c|c|}
\hline Jenis & $\begin{array}{c}\text { Derajat Esterifikasi } \\
(\%)\end{array}$ \\
\hline Pektin & 52,83 \\
Modifikasi & \\
\hline Pektin Markisa & 46,75 \\
Modifikasi & \\
\hline
\end{tabular}

Tabel 2 menunjukkan data hasil penentuan derajat esterifikasi pektin markisa tanpa modifikasi dan modifikasi. Derajat esterifikasi adalah rasio perbandingan antara grup asam galakturonat ester dan asam galakturonat keseluruhan [15].

Dari jumlah titrasi yang dilakukan pada pektin tanpa modifikasi jumlah grup karboksil dan grup ester lebih sedikit dari pektin modifikasi, sehingga dapat disimpulkan bahwa proses modifikasi pektin menambah jumlah grup karboksil dan grup ester. Selain itu dapat dilihat juga bahwa pada pektin tanpa modifikasi jumlah gugus ester lebih banyak daari jumlah gugus asam karbokilat tetapi sebaliknya pada pektin modifikasi, jumlah gugus ester lebih sedikit dari pada jumlah gugus asam karboksilat, sehingga dapat disimpulkan bahwa terjadi pergantian jenis pektin dari HMP menjadi LMP.

\section{Yield Pektin}

Untuk mengetahui jumlah yield dari pektin yang dihasilkan dapat menggunakan rumus 2 .

Yield $(\%)=\frac{\text { massa produk kering }}{\text { massa bahan kering }} \times 100$

Keterangan :

Yield : Yield yang dihasilkan (\%)

Massa produk kering : Massa kering produk (g)

Massa bahan kering : Massa kering bahan baku (g)

Dari hasil penelitian yang diperoleh yield pektin dari ekstraksi kulit markisa kuning adalah sebesar $2,54 \%$, sedangkan yield dari pektin modifikasi adalah sebesar

\section{Kesimpulan}

Hasil penelitian ini memberikan kesimpulan sebagai berikut :
1. Pektin tanpa modifikasi dan pektin modifikasi yang dihasilkan telah sesuai denga standar yang ada berdasarkan warna dan baunya.

2. Modifikasi pektin menambah jumlah asam karboksilat dan menghasilkan gugus baru pada pektin yaitu gugus aromatik.

3. Dari hasil penentuan derajat esterifikasi pektin diketahui terjadinya penurunan derajat esterifikasi dari jenis HMP (High Metoksil Pektin DE>50) ke jenis LMP (Low Metoksil Pektin DE<50).

4. Yield pektin hasil ekstraksi kulit markisa kuning adalah sebesar 2,54\% dan yield untuk pektin modifikasi adalah sebesar 94,73\%.

5. Semakin rendah kadar metoksil pektin maka sifat pembentukan jellinya akan semakin berkurang, sehingga dapat dikatakan bahwa pektin jenis LMP bisa digunakan sebagai adsorben logam berat dan agen anti kanker.

\section{Daftar Pustaka}

[1] Annisa Willy Halimas, Studi Morfologi dan Anatomi Beberapa Markisa Koleksi Balai Penelitian Tanaman Buah Kebun Percobaan Berastagi Sumatera Utara, Skripsi, Program Sarjana. Departemen Biologi Fakultas Matematika dan Ilmu Pengetahuan Alam Universitas Sumatera Utara, Medan, 2014.

[2] B. R. Sharma, Naresh L., N. C. Dhuldoya, S.U. Merchant and U. C. Merchant, Times Food Processing Journal, 7 (8) 2006, hal. 45.

[3] Donald L. Pavia, Gary M. Lampman, George S. Kriz, Introduction to Spectroscopy, Wahington: Thomson Learning, 2001.

[4] Evy Kurniawati, Kualitas Jelly Kulit Buah Markisa (Passiflora edulis var. flavicarpa Degener) dengan Variasi Suhu dan Waktu Ekstraksi Pektin, Skripsi, Program Sarjana Fakultas Teknobiologi Universitas Atmajaya, Yogyakarta, 2013.

[5] Farida Hanum, Martha Angelina Tarigan, Irza Menka Deviliany Kaban, Ekstraksi Pektin dari Kulit Buah Pisang Kepok (Musa paradisiaca), Jurnal Teknik Kimia USU, Vol. 23 (3) 2012, hal. 50.

[6] Indah Hartati dan Laeli Kurniasari, Enzymatic Extraction Of Low Methoxyl Pectin As A Potential Anti Cancer Agent From Green Cincau (Premna Oblongifolia Merr.), Prosiding Seminar Nasional Sains dan Teknologi ke-2, Juni, 2011, hal. B.33.

[7] L. Kurniasari, I. Riwayati, Suwardiyono, Pektin Sebagai Alternatif Bahan Baku Biosorben Logam Berat, Jurnal Momentum, 8(1) 2012 : hal. 1-5.

[8] M. Nasril Syah, Daya Serap Pektin dari Kulit Buah Durian (Durio zibethinus) Terhadap Logam Tembaga dan Seng, 
Skripsi, Program Sarjana Fakultas Farmasi USU, Medan, 2010.

[9] Norazelina Sah Mohd. Ismail, Nazaruddin Ramli, Norziah Mohd. Hani, Zainudin Meon, Sains Malaysiana, 41 (1) 2012, hal. 41-42.

[10] Pornsak Sriamornsak, Chemistry of Pectin and Its Pharmaceutical Uses : A Review, Thailand: Mahidol University, 2003.

[11] Prasad J, Fiji Agricultural Journal, 42 (1) 1980, hal. 45-48.

[12] S.Simmaky dan G. Jaanaki, Extraction and Characterization of Pectin from Yellow Passion Fruit (Passiflora edulis f.flavicarpa L) Endocarp Peel, SAITM Research on Engineering Advancement, Juni, 2014, hal. 27-28.

[13] Shan Qin Liew, Nyuk Ling Chin, Yus Aniza Yusof, Extraction and Characterization of Pectin from Passion Fruit Peels, Agriculture and Agricultural Science Procedia, Februari, 2014, hal. 231-236.

[14] Vita Fitria, Karakterisasi Pektin Hasil Ekstraksi dari Limbah Kulit Pisang Kepok (Musa balbisiana ABB), Skripsi, Program Sarjana Fakultas Kedokteran dan Ilmu Kesehatan UIN Syarif Hidayatullah, Jakarta, 2013.

[15] Y. N. Mata, M. L. Blazquez, A. Ballester, F. Gonzalez, J. A. Munoz, Sugar-beet Pulp Pectin Gels as Biosorbent for Heavy Metals: Preparation and Determination of Biosorption and Desorption Characterisrics, Jurnal Chemical Engineering, 150 (2009) 2009 : hal. 289-301. 